\title{
The clinical efficacy and safety of atropine combined with omeprazole in the treatment of patients with acute gastritis: a systematic review and meta-analysis
}

\author{
Xian Lin ${ }^{1 \#}$, Hao Chen ${ }^{1 \#}$, Yi-Nan Lin ${ }^{2}$ \\ ${ }^{1}$ Department of General Practice, Wenling First People's Hospital, Wenling, China; ${ }^{2}$ Department of Urology, Wenling First People's Hospital, \\ Wenling, China \\ Contributions: (I) Conception and design: X Lin; H Chen; (II) Administrative support: X Lin; H Chen; (III) Provision of study materials or patients: X \\ Lin; H Chen, YN Lin; (IV) Collection and assembly of data: X Lin; H Chen, YN Li; (V) Data analysis and interpretation: X Lin; H Chen, YN Li; (VI) \\ Manuscript writing: All authors; (VII) Final approval of manuscript: All authors. \\ \#These authors contributed equally to this work. \\ Correspondence to: Xian Lin; Hao Chen. Department of General Practice, Wenling First People's Hospital, No.333 South Chuan-an Road, Wenling, \\ China. Email: 504199660@qq.com; 16042470@qq.com.
}

Background: To date, guidelines on the impact and value of atropine combined with omeprazole in the treatment of acute gastritis have not been well established or well defined. This study aimed to clarify the efficacy and safety of combined atropine and omeprazole therapy for the management of patients with acute gastritis.

Methods: Through searching the electronic database, the related literature of the combination of atropine with omeprazole in the treatment of acute gastritis were reviewed. A meta-analysis was performed after literature selection according to inclusion criteria. The treatment efficiency and the incidence of adverse reactions were used as the main outcome indicators. The odds ratios (ORs), standardized mean differences (SMDs), and $95 \%$ confidence intervals (CIs) of the two treatment regimens were analyzed.

Results: This study analyzed 11 articles from the literature with a total of 1,053 subjects. The combination of atropine and omeprazole significantly improved the clinical outcomes of patients with acute gastritis compared to patients treated with combined anisodamine and omeprazole (control group). The effective rate of combined atropine and omeprazole treatment was 1.21 times higher than that observed with the control group, and the incidence of adverse reactions was 0.41 times that of the control group. Atropine combined with omeprazole significantly alleviated the clinical symptoms of the patients. The total treatment time was shortened by 0.57 days, duration of abdominal pain was shortened by 2.82 days, duration of diarrhea was reduced by 1.99 days, and the duration of nausea and vomiting was shortened by 2.68 days compared to the control group

Discussion: The combination of atropine with omeprazole in the treatment of acute gastritis demonstrated a high effective rate with few adverse reactions than. It was effective at alleviating the clinical symptoms associated with acute gastritis. The results of this study provide support for the clinical implementation of combined atropine and omeprazole in the treatment of patients with acute gastritis.

Keywords: Atropine; omeprazole; acute gastritis; anisodamine; meta-analysis

Submitted Jun 24, 2021. Accepted for publication Jul 28, 2021.

doi: 10.21037/apm-21-1868

View this article at: https://dx.doi.org/10.21037/apm-21-1868 


\section{Introduction}

Currently, the incidence of gastritis is about $10 \%$ worldwide, and continues to increase (1). Acute gastritis is a digestive system disease characterized by acute inflammatory lesions of the gastrointestinal mucosa. The integrity of the gastrointestinal mucosa is maintained by mucus, gastric epithelium, bicarbonate, and gastric mucosal blood flow. When the integrity of the mucosa is destroyed, aggressive factors such as pepsin, bile reflux, cigarettes, alcohol, nonsteroidal anti-inflammatory drugs, and Helicobacter pylori (2) can cause varying degrees of gastrointestinal damage (3). The main clinical manifestations are gastrointestinal symptoms such as abdominal pain, bloating, nausea, and vomiting. In some severe cases, hematemesis and gastric perforation may occur (4).

In daily clinical practice, more than $80 \%$ of acute and chronic gastritis and gastroduodenal infections are caused by $H$. pylori (5). H. pylori infection is an important pathogenic factor that causes mucosal inflammation, which can lead to acute gastritis, peptic ulcers, gastric malignant tumors and so on. Its pathogenic mechanisms are manifested by the obvious up-regulation of gastric mucosal endothelin-1 (ET-1) levels and pro-inflammatory cytokine expression $(6,7)$. Some studies have proposed symptomatic treatment by inhibiting $H$. pylori and repairing the gastric mucosa. Omeprazole is a proton pump inhibitor (PPI) widely used in clinical practice. This drug effectively suppresses acid production by inhibiting the activity of digestive enzymes such as $\mathrm{Na}^{+}-\mathrm{K}^{+}$-ATPase in gastric parietal cells, thereby greatly reducing the secretion of gastric acid and creating an optimal environment for the sterilization of drugs (8). Omeprazole can also protect the gastric mucosa, promote the recovery of metabolism of the gastric epithelial cells, and accelerate the alleviation of clinical symptoms. Both anisodamine and atropine are used clinically as antispasmodic agents. These are $M$ receptor antagonists, which have obvious effects on relaxing gastrointestinal smooth muscles and relieving gastrointestinal spasms and pain. In the past, atropine was commonly used in the rescue of toxic shock as it can effectively inhibit the absorption of poisons, thereby saving lives (9). In recent years, increasing numbers of researchers have proposed atropine for the treatment of acute gastritis. The reason is that atropine has strong selectivity for both excitatory smooth muscles and spastic smooth muscles, and its antispasmodic and analgesic effects are targeted (10). Recent studies (8) have suggested that the combination of $\mathrm{H} 2$ receptor blockers (such as omeprazole) with antispasmodic analgesics (such as atropine) may have good clinical efficacy. However, the efficacy and safety of combined omeprazole and atropine treatment remains controversial. This current meta-analysis reviewed the relevant literature and comprehensively analyzed and compared the clinical efficacy of combined atropine and omeprazole treatment with combined anisodamine and omeprazole treatment in the management of patients with acute gastritis.

We present the following article in accordance with the PRISMA reporting checklist (available at https://dx.doi. org/10.21037/apm-21-1868).

\section{Methods}

\section{Literature search}

Five electronic databases, including PubMed, Web of Science and Embase, CNKI, and the Wanfang database, were comprehensively searched for articles related to the treatment of acute gastritis using the combination of atropine with omeprazole (observation group) and anisodamine with omeprazole (control group). The following terms were used in the search text and medical subject terms (MeSH): "atropine", "omeprazole", and "acute gastritis". The databases were searched for reports published from 2010 to 2021, without any language restrictions. The references listed in the selected papers were reviewed for further relevant publications. Two researchers independently screened the papers (full text or abstract) to ensure that they meet the research criteria and eligibility. Quality assessments were performed on the selected studies. Any disagreements between the two researchers were resolved by consultation with a third investigator.

\section{Selection criteria}

This meta-analysis only evaluated studies involving atropine or anisodamine combined with omeprazole in the treatment of acute gastritis. Further studies were selected according to the following criteria: (I) the study involved original work and contained sufficient and relevant information for evaluation; (II) the study involved an experimental group in which patients were treated with atropine combined with omeprazole, and a control group in which patients were treated with anisodamine combined with omeprazole; and (III) the study was a randomized controlled trial (RCT). 
Exclusion criteria: (I) case reports, systematic reviews, and animal experiments; (II) the study which the original text could not be obtained; (III) the study with missing data; (IV) duplicate study.

\section{Data extraction}

The data extracted from the study contained basic information of the clinical study, including the first author, publication year, number of sample cases, patient enrollment time, and study type. Outcome indicators included treatment effectiveness, incidence of adverse reactions, total treatment time, duration of abdominal pain, duration of diarrhea, and duration of nausea and vomiting.

\section{Data analysis and evaluation of efficacy}

All data were analyzed using Stata 16.0 statistical software. The heterogeneity of the research data was assessed by calculating the $\mathrm{Q}$ statistic and the $\mathrm{I}^{2}$ statistic. $\mathrm{I}^{2}<50 \%$ was considered low heterogeneity, and $\mathrm{I}^{2}>50 \%$ was considered high heterogeneity. Based on the level of heterogeneity in the study, the fixed-effects model or the random-effects model was used. The study parameters of interest were as follows: the effective treatment rate, the rate of adverse reactions, total treatment time, duration of abdominal pain, duration of diarrhea, and duration of nausea and vomiting. Odds ratios (ORs) and 95\% confidence intervals (95\% CIs) were calculated. The publication bias of the selected literature was visualized using funnel plots. Sensitivity analysis was carried out by excluding each study and observing whether there were significant differences in the results, so as to evaluate the stability of the results.

\section{Results}

\section{Selection of literature}

A total of 374 records were identified from the databases using keyword searches. Following removal of duplicate records, there were 58 reports. An independent review of the titles and abstracts by 2 investigators resulted in the exclusion of 38 studies. After a review of the full text article of the remaining 20 studies, 9 reports were excluded due to insufficient data and/or duplication of data. Finally, a total of 11 studies were included in this meta-analysis $(8,11-20)$ (Figure 1).

\section{Analysis of the basic characteristics in the selected literature}

A total of 11 studies, comprising of 1,053 patients (Table 1), was included in this meta-analysis. There were 530 cases in the experimental group (atropine combined with omeprazole) and 523 cases in the control group (anisodamine combined with omeprazole). The study time ranged from 1 to 4 years. The patients ranged from 7.5 to 58.3 years old, with little difference in age distribution between the experimental group and the control group (7.5-51.9 and 7.5-58.3 years, respectively). There was no significant difference in the gender distribution between the two groups. The male to female ratio was $286: 244$ and 292:231 in the experimental and control groups, respectively. The basic characteristics of the two groups were highly comparable. All trials included data on 3 or more outcome variables.

\section{Primary outcomes}

There were 10 randomized controlled trials that examined the effective rate of treatment and the incidence of adverse reactions The heterogeneity between studies in terms of the treatment effective rate was not statistically significant ( $\mathrm{P}=0.574 ; \mathrm{I}^{2}=0.0 \%$; fixed-effect model). There was no significant heterogeneity in the incidence of adverse reactions $\left(\mathrm{P}=0.792 ; \mathrm{I}^{2}=0.0 \%\right.$; fixed effects model). Compared with the control group, atropine combined with omeprazole significantly improved the clinical efficacy for the treatment of acute gastritis, and the effective rate of treatment was 1.21 times higher than that observed with the control group $(\mathrm{OR}=1.21 ; 95 \% \mathrm{CI}: 1.15$ to $1.27 ; \mathrm{P}<0.05$; Figure $2 A$ ). In addition, atropine combined with omeprazole significantly prevented the incidence of adverse reactions in patients with acute gastritis ( $\mathrm{OR}=0.41 ; 95 \% \mathrm{CI}$ : 0.29 to 0.59; $\mathrm{P}<0.05$; Figure $2 B$ ). The publication bias of the study was evaluated, and the funnel plot showed that the effective scatter distribution of the treatment was asymmetrical, and thus, there was a certain degree of publication bias (Egger's test $\mathrm{P}<0.05$; Begg's test $\mathrm{P}<0.05$; Figure $3 A$ ). The incidence of adverse reactions showed a symmetrical distribution, with no significant publication bias (Egger's test $\mathrm{P}<0.05$; Begg's test $\mathrm{P}>0.05$; Figure $3 B$ ). Sensitivity analysis was further used to determine the stability of the meta-analysis results. The data showed that the range of effect values of treatment efficiency (Figure $4 A$ ) and adverse reaction rate (Figure $4 B$ ) in each study changed little, fluctuating around the comprehensive effect value, and the sensitivity was low, 


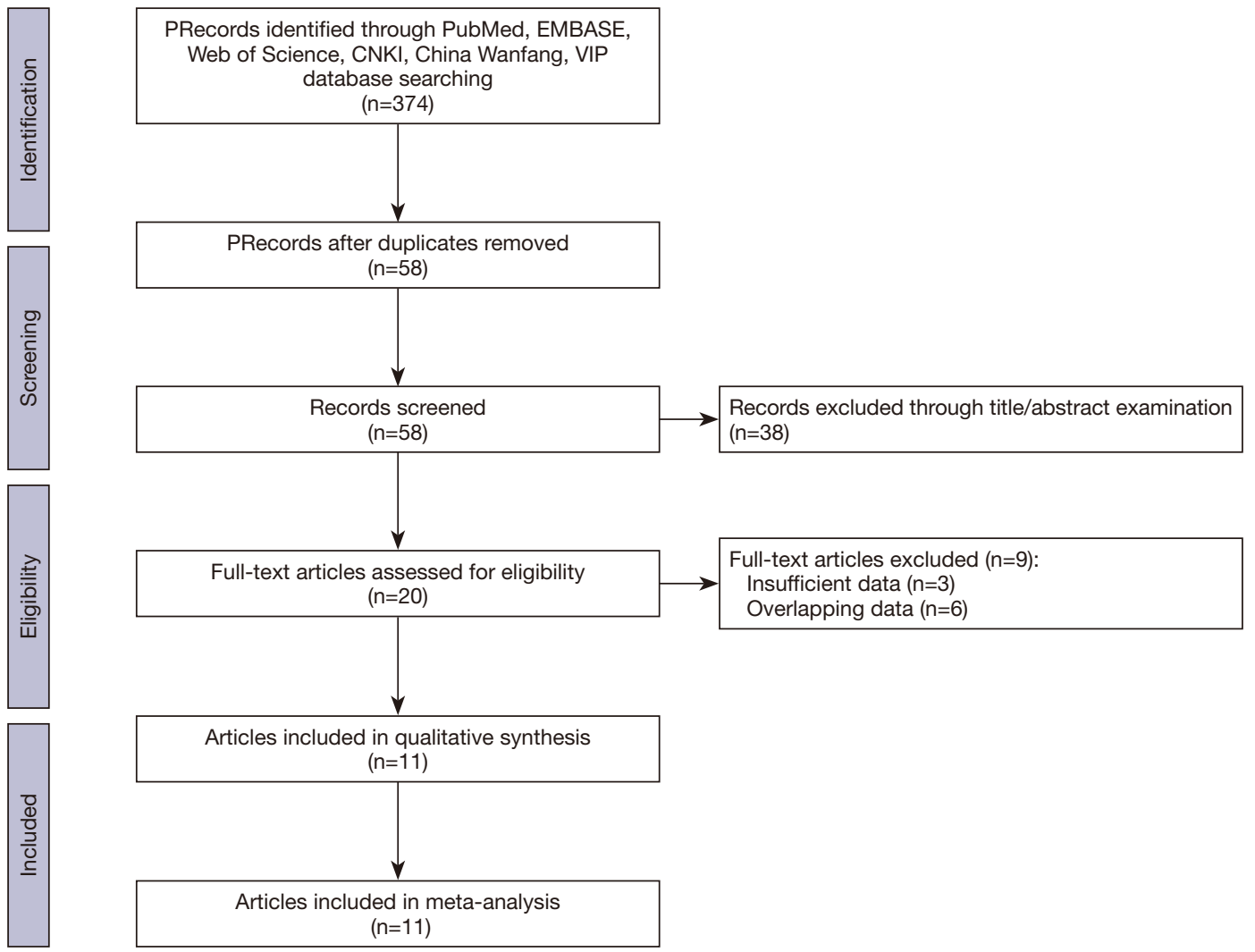

Figure 1 A flow diagram of the document retrieval process.

Table 1 The basic characteristics of the included literature

\begin{tabular}{|c|c|c|c|c|c|c|c|c|c|}
\hline \multirow{2}{*}{ First author } & \multirow{2}{*}{ Year } & \multirow{2}{*}{$\begin{array}{l}\text { Study time frame } \\
\text { (year, month) }\end{array}$} & \multirow{2}{*}{$\begin{array}{c}\text { Cases } \\
\text { treatment/ } \\
\text { control }\end{array}$} & \multicolumn{2}{|c|}{ Age (years) } & \multicolumn{2}{|c|}{$\begin{array}{c}\text { Gender distribution (male/ } \\
\text { female) }\end{array}$} & \multirow{2}{*}{$\begin{array}{l}\text { Study } \\
\text { design }\end{array}$} & \multirow{2}{*}{$\begin{array}{l}\text { Outcome } \\
\text { measures }\end{array}$} \\
\hline & & & & $\begin{array}{l}\text { Treatment } \\
\text { group }\end{array}$ & $\begin{array}{l}\text { Control } \\
\text { group }\end{array}$ & $\begin{array}{l}\text { Treatment } \\
\text { group }\end{array}$ & $\begin{array}{l}\text { Control } \\
\text { group }\end{array}$ & & \\
\hline Chen T (11) & 2015 & 2013.01-2014.06 & $50 / 50$ & $51.6 \pm 5.2$ & $52.6 \pm 3.1$ & $25 / 25$ & $25 / 25$ & $\mathrm{RCT}$ & (1)(2)(3) \\
\hline Li L (12) & 2019 & 2018.01-2018.12 & $48 / 48$ & $35.1 \pm 10.3$ & $42.2 \pm 5.2$ & $20 / 28$ & $25 / 23$ & $\mathrm{RCT}$ & (1)(4)(5) 6 \\
\hline Xu H (13) & 2017 & 2016.04-2017.04 & $36 / 34$ & $51.6 \pm 3.8$ & $51.8 \pm 3.7$ & $20 / 16$ & $19 / 15$ & $\mathrm{RCT}$ & (1)(2)(3) (4) 6 \\
\hline Kong D (14) & 2016 & 2013.06-2015.06 & $49 / 49$ & $7.5 \pm 13.2$ & $7.5 \pm 13.2$ & $28 / 21$ & $28 / 21$ & $\mathrm{RCT}$ & (1)(2)(4)(5) (6) \\
\hline Gong G (15) & 2016 & 2015.06-2016.01 & $67 / 67$ & $51.9 \pm 1.5$ & $52.0 \pm 1.3$ & $35 / 32$ & $37 / 30$ & $\mathrm{RCT}$ & (1)(2)(3) \\
\hline Hu R (16) & 2015 & 2010.03-2014.03 & $40 / 40$ & $46.5 \pm 3.4$ & $46.7 \pm 4.1$ & $23 / 17$ & $25 / 15$ & $\mathrm{RCT}$ & (1)(2)(3) \\
\hline Feng $\mathrm{H}(19)$ & 2020 & 2017.01-2019.02 & $43 / 43$ & $50.0 \pm 28.0$ & $49.5 \pm 27.5$ & $26 / 17$ & $25 / 18$ & $\mathrm{RCT}$ & (1)(2)(4)(5) 6 \\
\hline Wang A (20) & 2019 & 2016.02-2018.06 & $44 / 40$ & $43.7 \pm 7.9$ & $44.3 \pm 8.4$ & $23 / 21$ & $21 / 19$ & RCT & (1)(2)(3)(4)(5) 6 \\
\hline
\end{tabular}

(1) , effective rate of treatment; (2), adverse effects rate; (3), overall treatment time; (4), epigastric pain abatement time; (5) , diarrhea abatement time; (6), nausea and vomiting abatement time. RCT, randomized controlled trial; NR, not reported. 
A

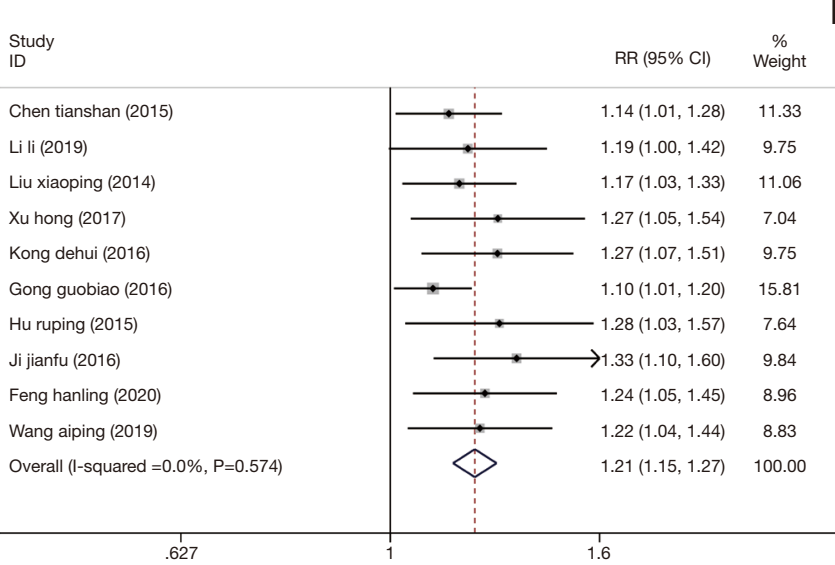

B

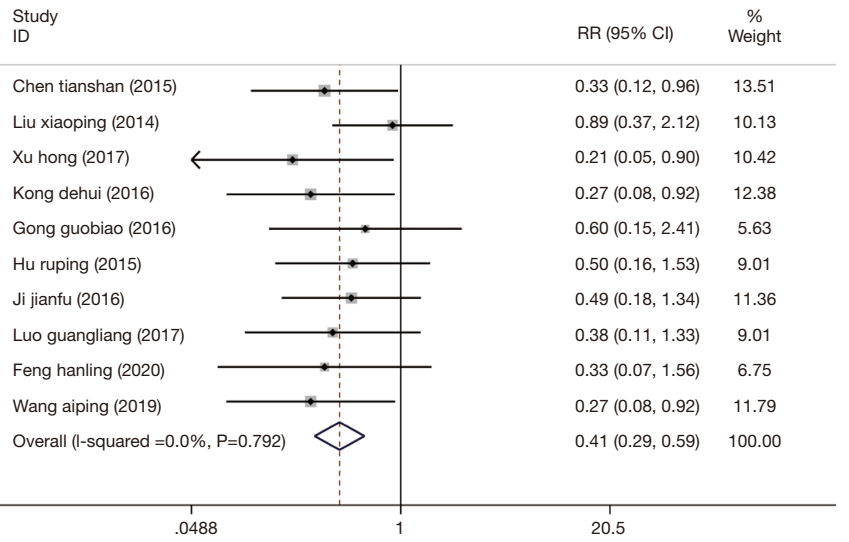

Figure 2 Forest plots of the main outcome indicators. (A) Treatment effective rate and (B) incidence of adverse reactions.
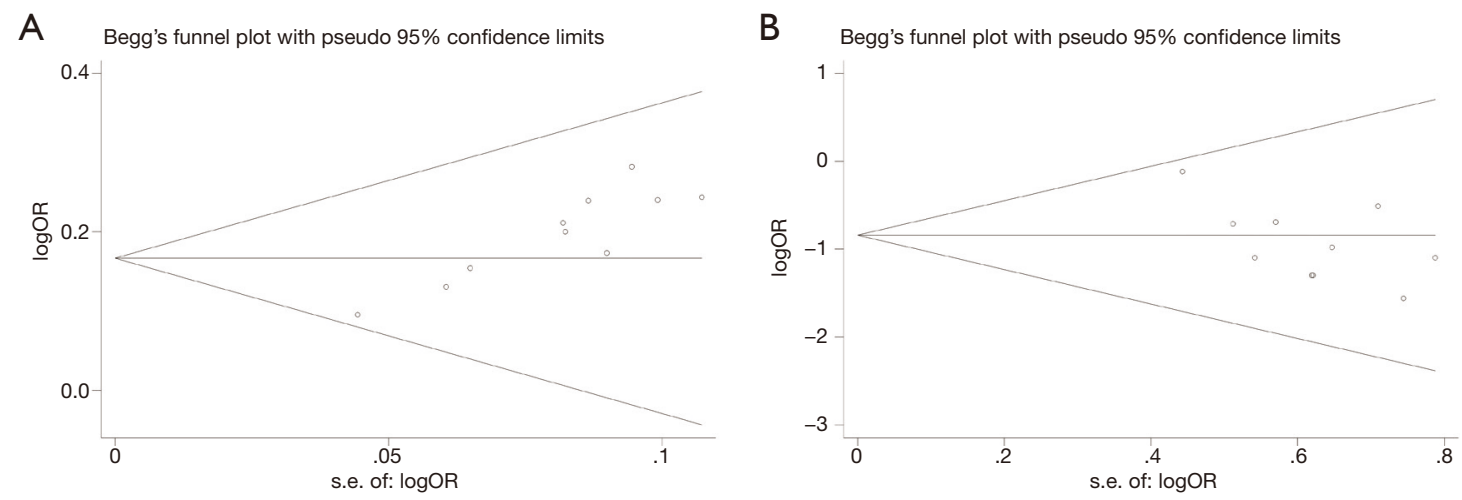

Figure 3 Funnel plots of main outcome indicators. (A) Treatment effective rate and (B) incidence of adverse reactions.
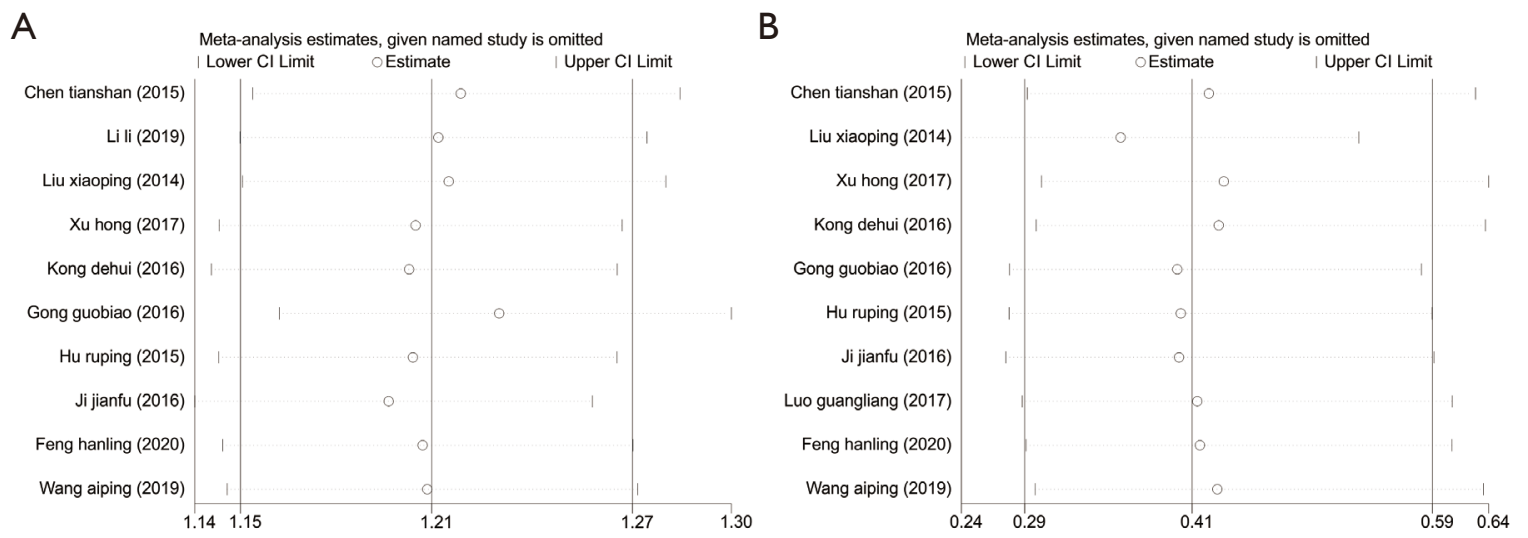

Figure 4 Sensitivity analysis plots of the main outcome indicators. (A) Treatment effective rate and (B) incidence of adverse reactions. 


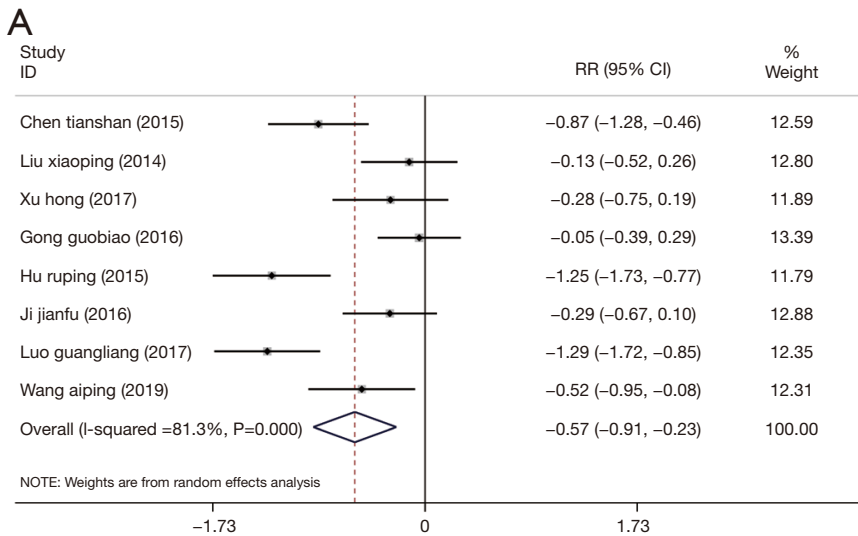

B
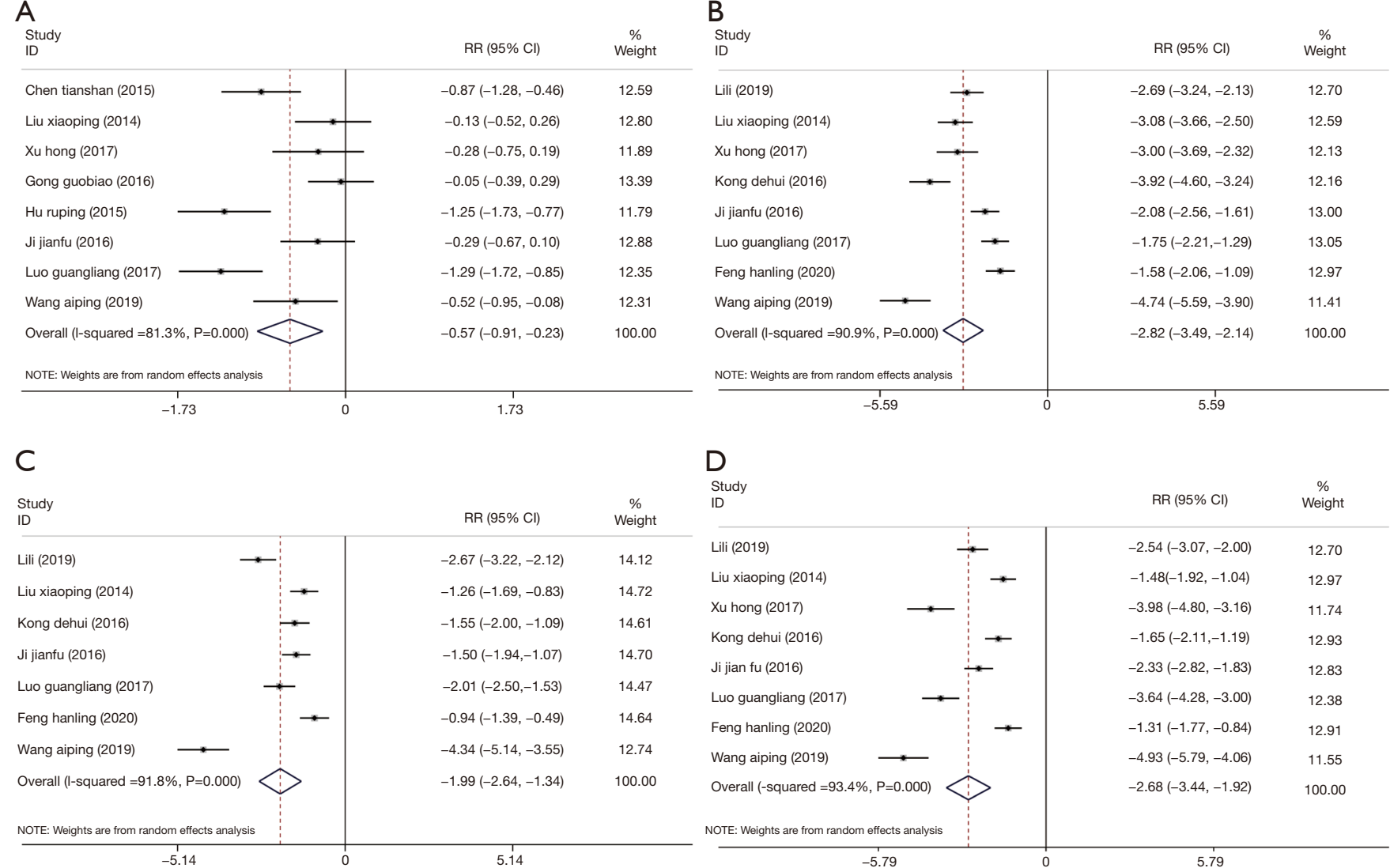

Figure 5 Forest plots of the secondary outcome indicators. (A) Total treatment time; (B) duration of abdominal pain; (C) duration of diarrhea; and (D) duration of nausea and vomiting.

which confirmed that the results of the meta-analysis were reliable.

\section{Secondary outcomes}

The four secondary outcomes involved the alleviation of common clinical symptoms. The heterogeneity of the studies was tested, and there was significant heterogeneity in all four indicators, including the total treatment time $\left(\mathrm{P}<0.05 ; \mathrm{I}^{2}=81.3 \%\right.$; random effects model $)$, duration of abdominal pain $\left(\mathrm{P}<0.05 ; \mathrm{I}^{2}=90.9 \%\right.$; random effects model), duration of diarrhea $\left(\mathrm{P}<0.05 ; \mathrm{I}^{2}=91.8 \%\right.$; random effects model), and duration of nausea and vomiting $\left(\mathrm{P}<0.05 ; \mathrm{I}^{2}=93.4 \%\right.$; random effects model $)$. Meta-analyses demonstrated that atropine combined with omeprazole significantly shortened the total treatment time for acute gastritis by 0.57 days compared to the control group [standardized mean difference $(\mathrm{SMD})=-0.57 ; 95 \% \mathrm{CI}$ : -0.91 to $0.23 ; \mathrm{P}<0.05$; Figure 5 A]. Atropine combined with omeprazole also shortened the duration of abdominal pain by 2.82 days ( $\mathrm{SMD}=-2.82$; $95 \% \mathrm{CI}:-3.49$ to 2.14 ; $\mathrm{P}<0.05$; Figure $5 B$ ), the duration of diarrhea by 1.99 days (SMD $=-1.99 ; 95 \%$ CI: -2.64 to $1.34 ; \mathrm{P}<0.05$; Figure 5C), and the duration of nausea and vomiting by 2.68 days (SMD $=-2.68 ; 95 \%$ CI: -3.45 to $1.92 ; \mathrm{P}<0.05$; Figure $5 D$ ). Since the number of articles that analyzed the 4 indicators was less than 10, there was a default publication bias, and thus, funnel plot analyses were not performed. Sensitivity analysis showed the total treatment time of each study (Figure 6A), the duration of abdominal pain (Figure $6 B$ ), the duration of diarrhea (Figure $6 C$ ), and the duration of nausea and vomiting (Figure $6 D$ ), all showed no significant changes in the range of effect values, with low sensitivity, confirming that the results of this meta-analysis were reliable.

\section{Discussion}

Acute gastritis is caused by acute inflammatory lesions of 
A

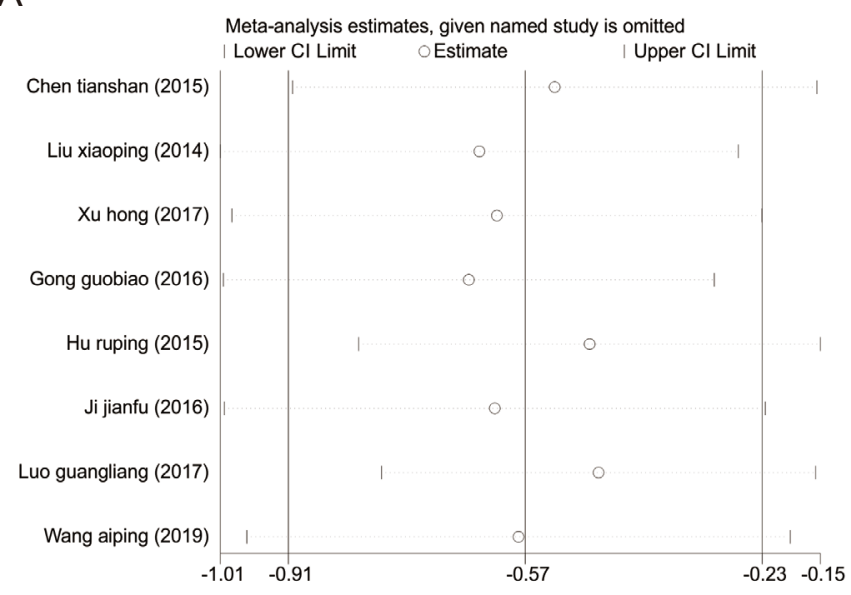

C

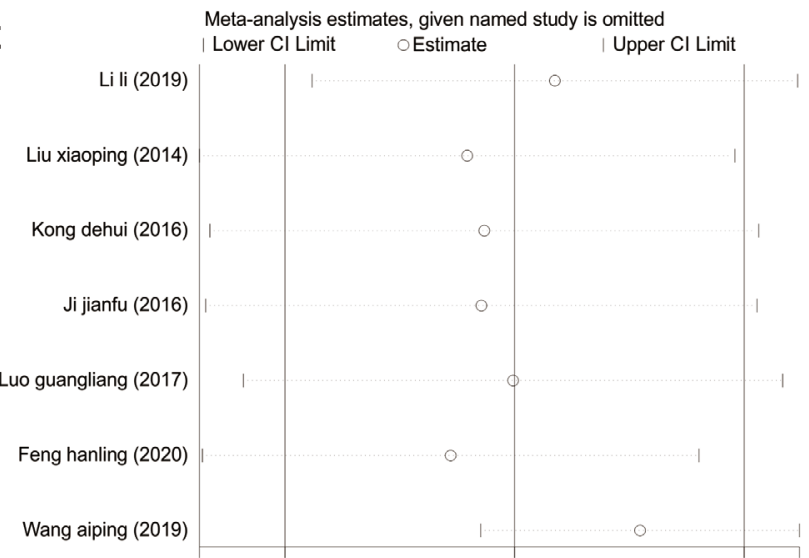

B
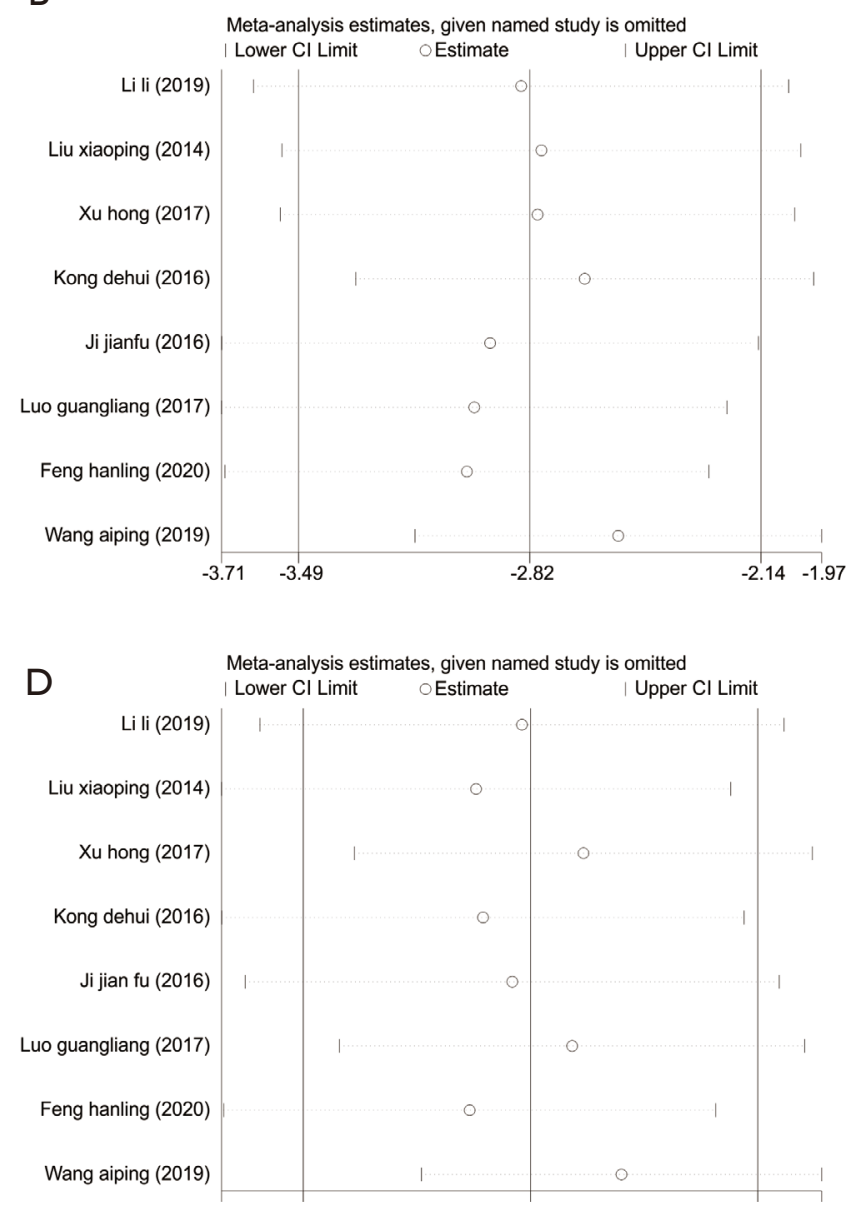

Figure 6 Sensitivity analysis of the secondary outcome indicators. (A) Total treatment time; (B) duration of abdominal pain; (C) duration of diarrhea; and (D) duration of nausea and vomiting.

the gastric mucosal epithelium due to the stimulation of a variety of pathogenic factors. With improved understanding of the pathogenic mechanisms of acute gastritis, the number of drugs available for treating acute gastritis has increased, but the clinical efficacy varies greatly. The key to successful management of acute gastritis lies in etiological and targeted treatment. Omeprazole is a proton pump inhibitor (PPI) widely used in the clinical setting. Since its development in 1979 , it has become one of the most commonly prescribed drugs worldwide (21), and has been listed on the WHO essential drugs list (22). Omeprazole is mainly used for the treatment of gastric acid related diseases, such as peptic ulcers, gastroesophageal reflux, gastrointestinal bleeding, and H. pylori infections. Treatment of H. pylori accounts for $34 \%$ of omeprazole prescriptions, and other gastritis-related diagnoses account for another $34 \%$ of all prescriptions (23). Omeprazole can be distributed in the secretory tubules of the gastric mucosal wall through blood circulation and it combines with the proton pump to inhibit the activity of the gastric acid pump and block the secretion of gastric acid (24). Anisodamine is an atropine derivative extracted from Eastern Guteng, which is mainly used to treat gastrointestinal smooth muscle spasms and myocardial infarction. Both anisodamine and atropine are non-specific cholinergic antagonists. Anisodamine is less potent and toxic than atropine, with the latter being more widely used in clinical and basic research (25). However, to date, it is unclear whether anisodamine or atropine has better efficacy when combined with omeprazole for the treatment of acute gastritis. This current meta-analysis was reported strictly in accordance with the PRISMA standard. The collection and analysis of data from previous literature 
allowed the objective assessment of the efficacy and safety of atropine combined with omeprazole in the treatment of acute gastritis.

This meta-analysis examined 11 articles, including 1,053 patients, and analyzed 2 primary outcomes and 4 secondary outcomes. Compared with the control group (anisodamine combined with omeprazole), atropine combined with omeprazole improved the clinical efficacy for the treatment of acute gastritis, and the treatment efficiency was 1.21 times that of the control group. At the same time, atropine combined with omeprazole decreased the incidence of adverse reactions of acute gastritis. Compared with the control group, atropine combined with omeprazole shortened the remission times of symptoms associated with acute gastritis. In patients treated with combined atropine and omeprazole, the total treatment time was 0.57 days shorter than that observed with the control group, the duration of abdominal pain was also shortened by 2.82 days, the duration of diarrhea was reduced by 1.99 days, and the duration of nausea and vomiting was decreased by 2.68 days.

This meta-analysis had several limitations. First, the treatment regimens examined only included atropine combined with omeprazole and anisodamine combined with omeprazole, and there was no comparison with any other common forms of treatment. Second, the age range of the participants was large (7.5 to 51.9 years old). Some of the included studies only reported the age range or the average age of the participants, hence, it was not possible to use subgroups to analyze the effect of age. Future studies should include a more clearly defined cohort with a tighter age range. Third, the results of some indicators showed comparatively high heterogeneity and may be affected by confounding factors such as age, gender, and race, and thus, there was a certain degree of bias. Fourth, all the literatures included in this study are in Chinese, which indicated that there was a language bias.

In summary, the combination of atropine and omeprazole could effectively alleviate the clinical symptoms in the treatment for acute gastritis and may be implemented in clinical practice. Future high-quality clinical trials in large scale settings are warranted to further establish and confirm the efficacy and safety of combined atropine and omeprazole for the management of patients with acute gastritis.

\section{Acknowledgments}

Funding: None.

\section{Footnote}

Reporting Checklist: The authors have completed the PRISMA reporting checklist. Available at https://dx.doi. org/10.21037/apm-21-1868

Conflicts of Interest: All authors have completed the ICMJE uniform disclosure form (available at https://dx.doi. org/10.21037/apm-21-1868). The authors have no conflicts of interest to declare.

Ethical Statement: The authors are accountable for all aspects of the work in ensuring that questions related to the accuracy or integrity of any part of the work are appropriately investigated and resolved.

Open Access Statement: This is an Open Access article distributed in accordance with the Creative Commons Attribution-NonCommercial-NoDerivs 4.0 International License (CC BY-NC-ND 4.0), which permits the noncommercial replication and distribution of the article with the strict proviso that no changes or edits are made and the original work is properly cited (including links to both the formal publication through the relevant DOI and the license). See: https://creativecommons.org/licenses/by-nc-nd/4.0/.

\section{References}

1. Díaz-Rivas JO, Herrera-Carrera E, Gallegos-Infante JA, et al. Gastroprotective potential of Buddleja scordioides Kunth Scrophulariaceae infusions; effects into the modulation of antioxidant enzymes and inflammation markers in an in vivo model. J Ethnopharmacol 2015;169:280-6.

2. Bie M, Wen J, Wang H, et al. Phylogenetic analysis of clinical strains of Helicobacter pylori isolated from patients with gastric diseases in Tibet. Ann Transl Med 2019;7:320.

3. Niu Q, Zhu J, Yu X, et al. Immune Response in H. pylori -Associated Gastritis and Gastric Cancer. Gastroenterol Res Pract 2020;28:9342563.

4. Liu F, Wang X, Yu X. Clinical features of acute gastritis. Modern Science 2015;2:62.

5. Suzuki H, Mori H. Helicobacter pylori: Helicobacter pylori gastritis--a novel distinct disease entity. Nat Rev Gastroenterol Hepatol 2015;12:556-7.

6. Camilo V, Sugiyama T, Touati E. Pathogenesis of Helicobacter pylori infection. Helicobacter 2017;22 Suppl $1: \mathrm{e} 12405$. 
7. Li J, Perez-Perez G. Helicobacter pylori the latent human pathogen or an ancestral commensal organism. Front Microbiol 2018;9:609.

8. Liu X. Clinical observation of atropine combined with omeprazole in the treatment of patients with acute gastritis. Medical Journal of Chinese People's Health 2014;24:58-9.

9. Wang J. Observation on the efficacy of atropine combined with omeprazole in the treatment for acute gastritis. Contemporary Medicine Forum 2014;13:156-7.

10. Li D. A comparative study of the therapeutic effects of atropine and anisodamine in patients with acute gastritis. Strait Pharmaceutical Journal 2015;27:91-2.

11. Chen T, Liang B, Huang $W$, et al. Clinical efficacy of atropine combined with omeprazole in the treatment of 100 patients with acute gastritis. Chinese Journal of New Clinical Medicine 2015;8:952-5.

12. Li L, Wen D, Li Y. Analysis of the clinical efficacy of atropine combined with omeprazole in the treatment of acute gastritis. The Medical Forum 2019;23:77-8.

13. $\mathrm{Xu} \mathrm{H}$. The clinical application of atropine and omeprazole in the treatment of acute gastritis. Journal of Hubei University for Nationalities (Medical Edition) 2017;034:79-80.

14. Kong D. Clinical observation on the treatment of acute gastritis with omeprazole and atropine. Clinical Research and Practice 2016;3:13-4.

15. Gong G, Liang J. Effect of anisodamine and omeprazole combined with atropine in treatment of patients with acute gastritis. Hainan Medical Journal 2016;27:2841-3.

16. Hu R. Observation on the clinical efficacy of atropine combined with omeprazole in treating acute gastritis. Chinese and Foreign Medical Research 2015;13:114-5.

17. Ji J. Effect of atropine and anisodamine in treating acute gastritis. Chinese Journal of Clinical Rational Drug Use 2016;3:35-6.

Cite this article as: Lin $\mathrm{X}$, Chen $\mathrm{H}$, Lin $\mathrm{YN}$. The clinical efficacy and safety of atropine combined with omeprazole in the treatment of patients with acute gastritis: a systematic review and meta-analysis. Ann Palliat Med 2021;10(9):9535-9543. doi: 10.21037/apm-21-1868
18. Luo G. Observation of the curative effect of atropine combined with omeprazole in the treatment of patients with acute gastritis and its influence on inflammatory factors. China Journal of Pharmaceutical Economics 2017;12:79-80.

19. Feng H. Analysis of Clinical Efficacy of Atropine combined with Omeprazole in Patients with Acute Gastritis. Guide of China Medicine 2020;18:103-4.

20. Wang A, Liu H, Liu W, et al. Analysis of the efficacy and safety of omeprazole combined with atropine and anisodamine in the treatment of acute gastritis. Modern Digestion \& Intervention 2019;12:1417-9.

21. Forgacs I, Loganayagam A. Overprescribing proton pump inhibitors. BMJ 2008;336:2-3.

22. Organization $\mathrm{W}$. WHO model list of essential medicines 20th edition. 2019.

23. Liu Y, Zhu X, Li R, et al. Proton pump inhibitor utilisation and potentially inappropriate prescribing analysis: insights from a single-centred retrospective study. BMJ Open 2020;10:e040473.

24. Wu J, Long E, Chen Z, et al. Comparison of Effectiveness of Omeprazole and Teprenone in Treatment of Chronic Superficial Gastritis. Sichuan Medical Journal 2014:35:331-3.

25. Grines C, Bonow R, Casey D, et al. Prevention of premature discontinuation of dual antiplatelet therapy in patients with coronary artery stents: a science advisory from the American Heart Association, American College of Cardiology, Society for Cardiovascular Angiography and Interventions, American College of Surgeons, and American Dental Association, with representation from the American College of Physicians. Catheter Cardiovasc Interv 2007;69:334-40.

(English Language Editor: J. Teoh) 